\title{
Inhibitory Effects of Eight Green Tea Catechins on Cytochrome P450 1A2, 2C9, 2D6, and 3A4 Activities
}

\author{
Takashi Satoh, Haruka Fujisawa, Ami Nakamura, Natsuko Takahashi and Kazuhiro Watanabe
}

Division of Pharmaceutics, Hokkaido Pharmaceutical University School of Pharmacy, Sapporo, Hokkaido 006-8590, Japan.

Received, February 22, 2016; Revised, May 24, 2016; Accepted, May 24, 2016; Published, May $26^{\text {th }}, 2016$.

\begin{abstract}
PURPOSE: Green tea is a traditional beverage that has been enjoyed by the Japanese to this day. Recently, there has been an increase in the consumption of green tea beverage having high concentrations of catechins, such as (-)-epigallocatechin-3-O-gallate (EGCG). Many people tend to ingest large amounts of catechins through the frequent consumption of green tea beverage, and this dietary habit may lead to unwanted interactions between the catechins in green tea and medicinal drug. METHODS: The inhibitory effects of eight green tea catechins on drug metabolizing enzymes, cytochrome P450 (CYP) 1A2, 2C9, 2D6, and 3A4, were investigated in human liver microsomes. Incubation was initiated by the addition of cocktail probe drugs that served as specific substrates for each CYP, and the resulting metabolites were analyzed by LC-MS. RESULTS: From a comparison of the fifty percent inhibitory concentration $\left(\mathrm{IC}_{50}\right)$ values of the eight green tea catechins, it was found that non-gallated catechins did not inhibit CYPs, whereas gallated catechins inhibited all CYPs except CYP2D6. Among them, CYP2C9 was most strongly inhibited by (-)-catechin-3-Ogallate $(\mathrm{CG})(7.60 \mu \mathrm{M})$, and CYP1A2 was most strongly inhibited by EGCG $(8.93 \mu \mathrm{M})$. Catechin gallate exhibited non-competitive inhibition of CYP2C9, and its $\mathrm{Ki}$ value was $9.76 \pm 0.47 \mu \mathrm{M}$. The present study is the first to report the inhibitory effect of CG on CYP2C9. In contrast, EGCG showed competitive inhibition of CYP1A2, and its $K$ i value was $14.3 \pm 0.09 \mu \mathrm{M}$. CONCLUSION: Previous reports had predicted that plasma EGCG concentration reached $7.4 \mu \mathrm{M}$ after ingesting green tea having high concentrations of catechins. That concentration of EGCG is equivalent to one-half to one-third of its $K$ i value for CYP1A2 and CYP3A4 in this study. The ingestion of beverages containing large amounts of green tea catechins together with drugs that are metabolized by CYP1A2, CYP2C9, and CYP3A4 should be avoided.
\end{abstract}

This article is open to POST-PUBLICATION REVIEW. Registered readers (see "For Readers") may comment by clicking on ABSTRACT on the issue's contents page.

\section{INTRODUCTION}

Food has three general functions. The first function is nutritional, which is essential for human survival. The second function is sensory satisfaction, such as deliciousness, flavor, and good texture. The third function is physiological, such as regulation of biorhythm, the nervous system, the immune system, and the host defense system. Dietary supplements, including functional foods, possess the third function and are expected to have a potentially positive effect on human health. Recent surveys have demonstrated that the prevalence of herbal products used as dietary supplements is approximately $20 \%$ and that the concurrent use of herbal products is noted in $20-30 \%$ of prescription drugs in the United States (1). According to surveys conducted in Japan, an estimated $75 \%$ of the population uses some form of dietary supplements
(2). Approximately $34 \%$ of users and $46 \%$ of the high-risk population, including obesity with prediabetes mellitus, lifestyle disease, and allergic diathesis, take dietary supplements together with prescription drugs. With the upsurge of the elderly population and the rapid transformation into an aging society in Japan, the consumption of prescription drugs has increased as well. It is reported that $78 \%$ of patients taking dietary supplements have not been checked for such by their caregiver.

Corresponding Author: Takashi Satoh; Division of Pharmaceutics, Hokkaido Pharmaceutical University School of Pharmacy, 7-15-4-1 Maeda, Teine, Sapporo, Hokkaido 0068590, Japan, E-mail: tsatoh@hokuyakudai.ac.jp 
Cytochrome P450 enzymes (CYPs) constitute the major enzyme family capable of catalyzing the oxidative biotransformation of steroid hormones (3), prostaglandins, bile acids, and xenobiotics, such as drugs. CYP families 1 to 3 have been shown to be of major importance in drug metabolism. The greatest contributor to the biotransformation of drugs is CYP3A4/5 (30.2\%), followed by CYP2D6 (20\%), CYP2C9 (12.8\%), CYP1A2 (8.9\%), and others (4). Clinically important interactions have been reported between dietary supplements, including functional food (5) and herbal products (6-8), and prescription drugs $(9, \quad 10)$. St. John's wort (Hypericum perforatum $\mathrm{L}$.), which is used in the management of mild depression, has been shown to adversely alter the pharmacokinetics of several prescription drugs. St. John's wort has been reported to lower blood cyclosporine level by $57 \%$ (11) and blood irinotecan level by $42 \%$ (12). These interactions have been suggested to be caused by the induction of hepatic CYP3A4.

The habit of drinking green tea (Sen-cha) prepared from Camellia sinensis (L.) Kuntze (Theaceae) as beverage has persisted among the Japanese for more than 1,000 years. Bitter and astringent ingredients, such as caffeine, and sweet and umami ingredients, such as theanine, an amino acid, are contained in green tea. These ingredients are responsible for the second function of food. Recently, flavan-3-ols, or the so-called catechins, including (-)-epigallocatechin-3-O-gallate (EGCG), have been valued as ingredients responsible for the third function of food. It has been reported that catechins reduce body fat and weight (12-15). On the basis of these reports, green tea beverages containing catechins, such as EGCG, were approved as Food for Specified Health Uses (FOSHU) (16) by the Consumer Affairs Agency of Japan, and were recommended for reducing body fat. As a result, people who drink these beverages in large quantities will be ingesting catechins in amounts never ingested before. Furthermore, according to a largescale cohort study conducted in Japan, high green tea or coffee consumption (over 2 cups/day) was beneficial for reducing the risk of cardiovascular disease, stroke, cerebral infarction, and intracerebral hemorrhage compared with 0 cup/day (17). With the release of this report, it is speculated that green tea consumption will further increase. On the other hand, such adverse events as jaundice, hepatitis, and acute liver failure caused by functional foods containing green tea extracts and their ingredients, including
EGCG, have been reported $(18,19)$. Therefore, unwanted drug interactions may occur when green tea beverage and medicinal drug are taken at the same time. Green tea catechins, the major components of which are (-)-epicatechin (EC), (-)epigallocatechin (EGC), (-)-epicatechin-3-O-gallate (ECG), and EGCG, are found in various tea products, such as green tea, oolong tea, and black tea (20). The consumption of canned and bottled green tea beverages is increasing in Asian countries, particularly in Japan. To pasteurize these products, autoclaving at $120^{\circ} \mathrm{C}$ for several minutes is carried out. However, autoclaving induces epimerization at position 2 of the C-ring of a large amount of catechins (around 50\%), forming (+)-catechin (C), (-)-gallocatechin (GC), (-)-catechin-3-O-gallate (CG), and (-)-gallocatechin-3-O-gallate (GCG) (21) (Figure 1).

The aim of the present study was to evaluate the inhibitory effects of eight catechins in green tea beverages on drug metabolizing enzymes, namely, cytochrome P450 (CYP) 1A2, CYP2C9, CYP2D6, and CYP3A4, in human liver microsomes. These four CYP isozymes were selected for study because they are related to a majority of the metabolic processes of drugs used in clinical practice $(4,22)$.

\section{METHODS}

\section{Materials}

EC, ECG, EGC, CG, GC, GCG, phenacetin, diclofenac sodium, and midazolam were purchased from Wako Pure Chemical Industries (Osaka, Japan). Ketoconazole was purchased from Tokyo Chemical Industry (Tokyo, Japan). Acetaminophen, furafylline, sulfaphenazole, quinidine hydrochloride monohydrate, and 1'-hydroxymidazolam were purchased from Sigma-Aldrich (St. Louis, MO, U.S.A.). EGCG was purchased from Nacalai Tesque (Kyoto, Japan). C was purchased from ChromaDex (Irvine, CA, U.S.A.). Bufuralol hydrochloride and 1'-hydroxybufuralol were purchased from Toronto Research Chemicals (Toronto, Ontario, Canada). 4'Hydroxydiclofenac and pooled human liver microsomes, BD Ultra Pool ${ }^{\mathrm{TM}}$ HLM 150 (lot no. 38291), were purchased from Corning Gentest (Woburn, MA, U.S.A.). $\beta$-Nicotinamide-adenine dinucleotide phosphate sodium salt $\left(\beta-\mathrm{NADP}^{+}\right)$, Dglucose-6-phosphate sodium salt (G-6-P), and glucose-6-phosphate dehydrogenase (G-6-PDH) were purchased from Oriental Yeast (Tokyo, Japan). 
<smiles>C[C@H]1Cc2c(O)cc(O)cc2O[C@H]1c1ccc(O)c(O)c1</smiles>

(+)-Catechin (C)<smiles>Oc1cc(O)c2c(c1)O[C@H](c1ccc(O)c(O)c1)[C@H](O)C2</smiles>

(-)-Epicatechin (EC)<smiles>O=C(O[C@H]1Cc2c(O)cc(O)cc2O[C@H]1c1ccc(O)c(O)c1)c1cc(O)c(O)c(O)c1</smiles>

(-)-Catechin-3-O-gallate (CG)<smiles>O=C(O[C@H]1Cc2c(O)cc(O)cc2O[C@H]1c1ccc(O)c(O)c1)c1cc(O)c(O)c(O)c1</smiles>

(-)-Epicatechin-3-O-gallate (ECG)<smiles>Oc1cc(O)c2c(c1)O[C@H](c1cc(O)c(O)c(O)c1)[C@H](O)C2</smiles>

(-)-Gallocatechin (GC)<smiles>Oc1cc(O)c2c(c1)O[C@H](c1cc(O)c(O)c(O)c1)[C@H](O)C2</smiles>

(-)-Epigallocatechin (EGC)<smiles>O=C(O[C@H]1Cc2c(O)cc(O)cc2O[C@H]1c1cc(O)c(O)c(O)c1)c1cc(O)c(O)c(O)c1</smiles>

(-)-Gallocatechin-3-O-gallate (GCG)<smiles>O=C(O[C@H]1Cc2c(O)cc(O)cc2O[C@H]1c1cc(O)c(O)c(O)c1)c1cc(O)c(O)c(O)c1</smiles>

(-)-Epigallocatechin-3- $O$-gallate (EGCG)

Figure 1. Chemical structures of green tea catechins 
All other chemicals used in the experiments were of the highest purity commercially available.

\section{Inhibition Assay}

The incubation of CYP was performed by following a previously reported method with slight modification (23). The specific substrates and inhibitors of each CYP isoform and their concentrations used in this study, which have been recommended by the US Food and Drug Administration (24), were used in the inhibition assay. Incubation mixtures containing $50 \mathrm{mM}$ Tris$\mathrm{HCl}$ buffer ( $\mathrm{pH} 7.4), 0.2 \mathrm{mg}$ protein $/ \mathrm{mL}$ pooled human liver microsomes, and green tea catechins $(\mathrm{C}$, EC, GC, EGC, CG, ECG, GCG or EGCG) were kept on ice. A pre-incubation of $5 \mathrm{~min}$ at $37^{\circ} \mathrm{C}$ was performed after adding an NADPH generating system (1.3 mM $\beta$-NADP ${ }^{+}, 3.3 \mathrm{mM}$ G-6-P, 0.4 unit $/ \mathrm{mL}$ G-6-PDH, and $3.3 \mathrm{mM} \mathrm{MgCl}_{2}$ ). The incubation was initiated by the addition of cocktail probe drugs $(40 \mu \mathrm{M}$ phenacetin for CYP1A2, $2 \mu \mathrm{M}$ diclofenac for CYP2C9, $10 \mu \mathrm{M}$ bufuralol for CYP2D6, and $2 \mu \mathrm{M}$ midazolam for CYP3A4), and performed for $30 \mathrm{~min}$ at $37^{\circ} \mathrm{C}$. The concentrations of the cocktail probe drugs were nearly the same as the apparent Michaelis constant $(\mathrm{Km})$ values of the CYPs reported previously (23). The final incubation volume was $250 \mu \mathrm{L}$, and green tea catechins and all the substrates were dissolved in methanol (final concentration, $1.0 \mathrm{vol} \%$ ). Control incubations were carried out in the absence of green tea catechins but using the same volume of methanol. The reaction was terminated by adding $250 \mu \mathrm{L}$ of ice-cold acetonitrile/methanol $(1: 1, \mathrm{v} / \mathrm{v})$ to the incubation mixture. Precipitated proteins were removed by centrifugation for $5 \mathrm{~min}$ at $10,000 \mathrm{rpm}$, and the supernatant was filtered through $0.45 \mu \mathrm{m}$ membrane filter. The filtrate was injected into a liquid chromatograph-mass spectrometer (LC-MS). Except for the addition of selective inhibitors (furafylline for CYP1A2, sulfaphenazole for CYP2C9, quinidine for CYP2D6, and ketoconazole for CYP3A4) instead of green tea catechins, the incubation was performed in the same manner as that described above.

\section{LC-MS}

A $2 \mu \mathrm{L}$ portion of the filtrate was applied to a reversed-phase column $(1.8 \mu \mathrm{m}$ particle size, $50 \times$ $2.1 \mathrm{~mm}$, i.d.; ACQUITY UPLC HSS T3, Waters, Milford, MA, U.S.A.) equipped with a guard column $(1.8 \mu \mathrm{m}, 5 \times 2.1 \mathrm{~mm}$, i.d.; VanGuard, Waters $)$ at the constant temperature of $45^{\circ} \mathrm{C}$. The mass spectra of acetaminophen, 4'-hydroxydiclofenac, 1'hydroxybufuralol, and 1'-hydroxymidazolam were measured with an LC-MS system (LCMS-2020 equipped with a model LC-20AD dual pump and an SPD-M20A UV detector at $254 \mathrm{~nm}$ (Shimadzu, Japan)). The eluents were formic $\mathrm{acid} /$ acetonitrile/water $(0.1: 5: 95, \mathrm{v} / \mathrm{v} / \mathrm{v}) \quad(\mathrm{A})$ and formic acid/acetonitrile/water (0.1:98:2) (B), and the gradients were as follows: $0-0.6 \mathrm{~min}, 8 \% \mathrm{~B} ; 0.6-1.0$ min, 8-30\% B; 1.0-3.5 min, 30-45\% B; 3.5-5.0 min, $45-80 \% \mathrm{~B}$; and $5.0-7.0 \mathrm{~min}, 80-100 \% \mathrm{~B}$ at the flow rate of $0.3 \mathrm{~mL} / \mathrm{min}$. LC-MS analysis was performed in the positive electrospray ionization interface with probe voltage set at $-3.5 \mathrm{kV}$ and desolvation line and block heater temperatures set at $250^{\circ} \mathrm{C}$ and $400^{\circ} \mathrm{C}$, respectively. Nitrogen was used as the nebulizing and drying gas at the flow rates of $1.5 \mathrm{~L} / \mathrm{min}$ and 15 $\mathrm{L} / \mathrm{min}$, respectively. Target ions of acetaminophen, 4'-hydroxydiclofenac, 1'-hydroxybufuralol, and 1'hydroxymidazolam were set at $m / z 152,312,279$, and 342, respectively. Chromatographic analysis was carried out on Shimadzu model 2020 data analysis software Lab Solutions Version 5.55.

\section{DATA ANALYSIS}

Values are shown as means \pm S.D. and the difference between groups was tested with Stat Flex Ver. 6.0 (Artec, Osaka, Japan). To test the difference between two independent groups, variance was examined with the F-test. If the variances were equal, the Student's t-test was applied. If the variances were not equal, the Welch t-test was applied. To test the differences among three independent groups, oneway analysis of variance (ANOVA) was performed if the variances were equal as determined by Bartlett's test. If a statistically significant difference was noted and the sample number was the same among the groups, Dunnett's multiple comparison test was performed. In addition, if the variances were not equal as determined by Bartlett's test, the Kruskal-Wallis test was performed, and if a significant difference was noted, Scheffe's multiple comparison test was applied. For each test, the significance level was set at $p<0.05$.

\section{RESULTS}

\section{Determination of Inhibitory Concentration}

The inhibitory effects of the eight green tea catechins on acetaminophen deethylation, diclofenac 4'hydroxylation, bufuralol 1'-hydroxylation, and midazolam 1'-hydroxylation mediated by CYP1A2, 
CYP2C9, CYP2D6, and CYP3A4, respectively, were investigated. The control activities of CYP1A2, CYP2C9, CYP2D6, and CYP3A4 in human liver microsomes were $215.0 \pm 14,274.0 \pm 2.6,42.5 \pm$ 1.37 , and $154.0 \pm 3.9 \mathrm{pmol} / \mathrm{mg}$ protein $/ \mathrm{min}$, respectively. The concentration-dependent inhibition curves are shown in Figure 2. Fifty percent inhibitory concentration $\left(\mathrm{IC}_{50}\right)$ values of the catechins for CYPs in human liver microsomes are shown in Table 1. Catechin gallate showed the strongest inhibitory effect on CYP2C9 $(7.60 \mu \mathrm{M})$, followed by EGCG on CYP1A2 $(8.93 \mu \mathrm{M})$ and CYP3A4 $(23.7 \mu \mathrm{M})$, GCG on CYP2C9 $(26.8 \mu \mathrm{M})$ and CYP1A2 $(28.3 \mu \mathrm{M})$, ECG on CYP2C9 (31.1 $\mu \mathrm{M})$, EGCG on CYP2C9 $(39.1 \mu \mathrm{M})$, and GCG on CYP3A4 $(40.8 \mu \mathrm{M})$. These four green tea catechins (CG, ECG, GCG, and EGCG), which had a galloyl moiety in the C-ring (Figure 1), showed significant inhibitory effects on CYP1A2, CYP2C9, and CYP3A4 (except ECG on CYP1A2 and CYP3A4), but not on CYP2D6. Catechins without the galloyl moiety (C, EC, GC, and EGC) did not show any inhibitory effects on all CYPs at the concentrations of 1 to $100 \mu \mathrm{M}$.

To compare inhibition intensity, the $\mathrm{IC}_{50}$ values of the selective inhibitors of CYPs were measured. Instead of green tea catechins, furafylline, a CYP1A2 specific inhibitor; sulfaphenazole, a CYP2C9 specific inhibitor; quinidine, a CYP2D6 specific inhibitor; and ketoconazole, a CYP3A4 specific inhibitor, significantly and markedly inhibited their corresponding CYPs, and the $\mathrm{IC}_{50}$ values were $1.40,0.81,0.09$, and $0.06 \mu \mathrm{M}$, respectively (Table 1$)$.

\section{Inhibition Constant and Inhibition Type}

The $\mathrm{IC}_{50}$ values of CG and EGCG for CYP2C9 and CYP1A2, respectively, were less than $10 \mu \mathrm{M}$. Then, the Dixon plots were analyzed to clarify the types of inhibition and the inhibition constant $(K \mathrm{i})$ of $\mathrm{CG}$ and EGCG for CYP2C9 and CYP1A2, respectively. Ki of EGCG for CYP3A4, the most abundant CYP form in liver, was determined (4). The concentrations of the cocktail probe drugs were set to $1 / 2 \times K \mathrm{~m}, \mathrm{Km}$, and $2 \times \mathrm{Km}$ as described under "METHODS". Catechin gallate and EGCG showed non-competitive inhibition of CYP2C9 and CYP3A4, respectively (Figure 3), and the corresponding $K$ i values were $9.76 \pm 0.47$ and 20.1 $\pm 0.30 \mu \mathrm{M}$ (Table 2). In contrast, EGCG showed competitive inhibition of CYP1A2 and Ki was 14.3 $\pm 0.09 \mu \mathrm{M}$.

On the other hand, selective inhibitors sulfaphenazole, furafylline, and ketoconazole showed competitive inhibition of CYP1A2, CYP2C9, and CYP3A4, respectively, and the corresponding $K \mathrm{i}$ values were $0.65 \pm 0.16,0.67 \pm$ 0.01 , and $0.05 \pm 0.01 \mu \mathrm{M}$.

\section{DISCUSSION}

As shown in Figure 1, the eight green tea catechins possess a polyphenolic structure, including two hydroxyl groups in the A-ring and two or three hydroxyl groups in the B-ring. These catechins can be divided into two groups according to the presence or absence of a gallate group at position 3 of the Cring. The $\mathrm{IC}_{50}$ values of the catechins for CYP1A2, CYP2C9, CYP2D6, and CYP3A4 confirmed that the inhibitory effects of non-gallated catechins, including C, EC, GC and EGC, were weak (Table 1). Our results were consistent with the previous report of Muto et al. (25), who indicated that EC and EGC did not show any inhibitory effects on CYP1A1, CYP1A2, CYP2A6, CYP2C9, CYP2E1, and CYP3A4 expressed in the membrane fraction of genetically engineered Salmonella typhimurium TA1538 cells. Thus, these results indicated that nongallated catechins are unlikely to alter the disposition of drugs on these major CYPs.

In contrast, gallated catechins, such as CG, ECG, GCG, and EGCG, inhibited CYP1A2, CYP2C9, and CYP3A4 but not CYP2D6, suggesting that the interaction between green tea catechins and therapeutic drugs metabolized by hepatic CYP2D6, such as antiarrhythmics, antidepressants, antipsychotics, $\beta$-blockers, anticancer drugs, and opioid analgesics (4), did not occur. The inhibitory effects on CYP1A2 and CYP3A4 were greater for GCG and EGCG having a 5'-OH group in the B-ring than for CG and ECG that had no 5'-OH group in the B-ring. As shown in Figure 3 and Table 2, the apparent $K \mathrm{i}$ value of EGCG for CYP3A4, which is estimated to account for approximately $30 \%$ of human liver CYP content (4), was $20.1 \pm 0.30 \mu \mathrm{M}$. Previous studies had indicated that CYP3A4mediated midazolam 1'-hydroxylation was noncompetitively inhibited by EGCG, and their $\mathrm{Ki}$ values $(13.0 \mu \mathrm{M}(25)$ and $17.7 \mu \mathrm{M}$ (26)) were consistent with our result.

Furthermore, the $K \mathrm{i}$ value of EGCG for CYP1A2-mediated 7-ethoxyresorufin $O$ deethylation was $9.50 \mu \mathrm{M}$, in good agreement with our result, but the inhibition type was noncompetitive (25). 

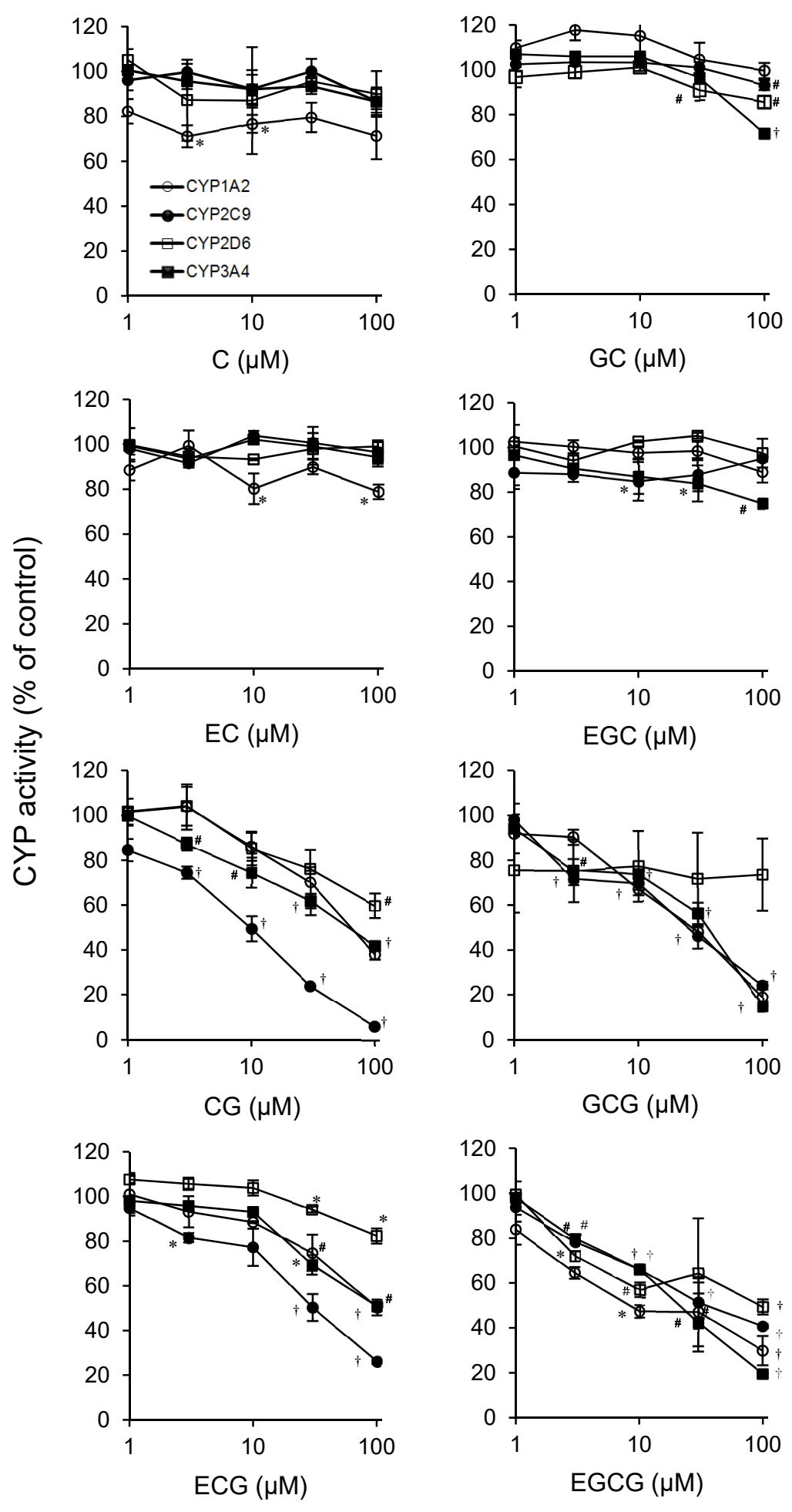

Figure 2. Concentration-dependent inhibition curves of eight green tea catechins for each CYP activity in human liver microsomes. The control activities of CYP1A2, CYP2C9, CYP2D6, and CYP3A4 were 215.0 $\pm 14,274.0 \pm 2.6,42.5 \pm$ 1.37 , and $154.0 \pm 3.9 \mathrm{pmol} / \mathrm{min} / \mathrm{mg}$ protein, respectively. Each value represents the mean \pm S.D. of triplicate determinations. Significantly different from control, ${ }^{*} p<0.05, \# p<0.01,{ }^{t} p<0.001$. 
Table 1. $\mathrm{IC}_{50}$ values of eight green tea catechins and selective inhibitors for CYPs in human liver microsomes. $\mathrm{IC}_{50}$ values were determined from the data shown in Figure 2. Selective inhibitors were furafylline, sulfaphenazole, quinidine, and ketoconazole for CYP1A2, CYP2C9, CYP2D6, and CYP3A4, respectively. Each value represents the mean of triplicate determinateions.

\begin{tabular}{lllll}
\hline \multirow{2}{*}{ Catechin } & \multicolumn{1}{l}{$\mathrm{IC}_{50}(\mu \mathrm{M})$} & & \\
\cline { 2 - 5 } & $\mathrm{CYP1A2}$ & $\mathrm{CYP} 2 \mathrm{C} 9$ & $\mathrm{CYP} 2 \mathrm{D} 6$ & $\mathrm{CYP3A4}$ \\
\hline $\mathrm{C}$ & $>100$ & $>100$ & $>100$ & $>100$ \\
$\mathrm{EC}$ & $>100$ & $>100$ & $>100$ & $>100$ \\
GC & $>100$ & $>100$ & $>100$ & $>100$ \\
EGC & $>100$ & $>100$ & $>100$ & $>100$ \\
CG & $74.1 \pm 1.61$ & $7.60 \pm 0.38$ & $>100$ & $71.5 \pm 7.51$ \\
ECG & $>100$ & $31.1 \pm 1.66$ & $>100$ & $>100$ \\
GCG & $28.3 \pm 1.73$ & $26.8 \pm 5.75$ & $>100$ & $40.8 \pm 6.93$ \\
EGCG & $8.93 \pm 1.03$ & $39.1 \pm 2.46$ & $97.2 \pm 3.11$ & $23.7 \pm 1.54$ \\
\hline Selective Inhibitor & $1.40 \pm 0.09$ & $0.81 \pm 0.11$ & $0.09 \pm 0.02$ & $0.06 \pm 0.00$ \\
\hline
\end{tabular}

On the other hand, regardless of the 5'-OH group in the B-ring, these four gallated catechins demonstrated relatively strong inhibitory effects on CYP2C9. Among them, CG exhibited the most potent inhibitory effect. Epicatechin gallate, an epimer of $\mathrm{CG}$, has a different steric configuration of the B-ring, but its effect was similar to that of GCG and EGCG. Based on the $K \mathrm{i}$ value of $\mathrm{CG}$ for CYP2C9 of $9.76 \mu \mathrm{M}$ and the $K \mathrm{i}$ value of the selective inhibitor of CYP2C9, sulfaphenazole, 0.67 $\mu \mathrm{M}$, the ratio of inhibitory intensity ( $\mathrm{CG} /$ selective inhibitor) was approximately 14 . This ratio was lower than those of EGCG/furafylline for CYP1A2 and EGCG/ketoconazole for CYP3A4 (22 and 400, respectively). Compared with EGCG that has many biological effects, little is known of the effects of CG.

Some studies have reported that $\mathrm{CG}$ exerts an anticarcinogenic effect $(27,28)$ and a glucose uptake suppression effect on adipocytes (29). To our knowledge, the present study is the first to report the inhibitory effect of CG on CYP2C9.

Imai et al. (30) reported that $28 \%$ of Japanese aged 60 years or over consumed 10 or more cups of green tea a day. They estimated that 10 cups of green tea would supply 300-400 mg of EGCG, assuming $150 \mathrm{~mL}$ of green tea per cup. Nakagawa et al. (31) reported that plasma EGCG concentration was significantly and dose-dependently increased, reaching approximately $4.4 \mu \mathrm{M}$ at $90 \mathrm{~min}$ after ingestion of green tea extract containing $525 \mathrm{mg}$ of
EGCG in healthy subjects. Chow et al. (32) reported that peak plasma concentration was $7.4 \mu \mathrm{M}$ after a single dose of 1,200 $\mathrm{mg}$ of EGCG in human.

Therefore, the ingestion of large quantities of green tea might yield plasma EGCG concentrations similar to those in previous report (32), which corresponded to one-half to one-third of the $K$ i value of EGCG for CYP1A2 and CYP3A4 in this study.

Interestingly, gallated catechins, such as EGCG, were detected in human plasma mostly in the unchanged form, whereas non-gallated catechins, such as EGC and EC, were detected mostly as glucuronide and sulfate conjugated forms. Over $90 \%$ of the total urinary EGC and EC, almost all in the conjugated forms, were excreted between 0 and $8 \mathrm{hr}$ $(33,34)$. These results suggested that gallated catechins were circulating in the unchanged form in plasma, and thus might induce food-drug interactions mediated by CYP1A2 and CYP3A4 in liver, particularly CYP1A2, which showed competitive inhibition. Chow et al. (35) evaluated the effects of EGCG on CYP1A2, CYP2C9, CYP2D6, and CYP3A4 in forty-two healthy volunteers administered $800 \mathrm{mg}$ of EGCG for four weeks. The phenotypic indexes of CYP1A2, CYP2D6, and CYP2C9 were not altered, but the area under the plasma buspirone concentration-time profile was increased by $20 \%(p=0.01)$ compared with baseline, suggesting a slight reduction in CYP3A4 activity. 

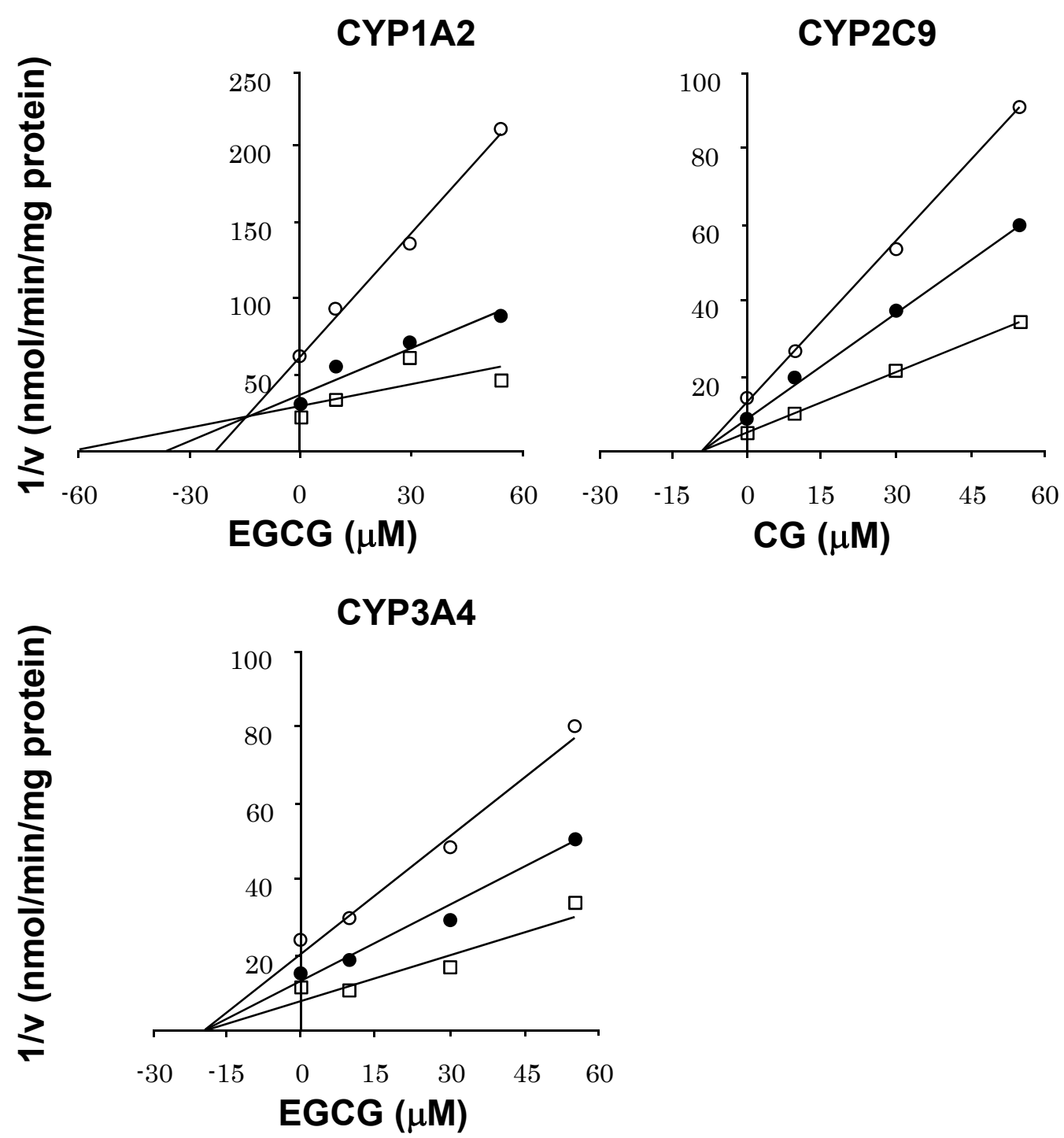

Figure 3. Dixon plots of EGCG for CYP1A2 and CYP3A4, and CG for CYP2C9 in human liver microsomes. The concentrations of cocktail probe drugs were set to $1 / 2 \times K \mathrm{~m}(\circ), K \mathrm{~m}(\bullet)$, and $2 \times K \mathrm{~m}(\square)$ as described in Methods. Each value represents the mean of triplicate determinations.

Table 2. Apparent $K \mathrm{i}$ values of CG, EGCG, and selective inhibitors for CYP in human liver microsomes. Apparent $K$ i values were determined from the data shown in Figure 3. Selective inhibitors were furafylline $(0-10$ $\mu \mathrm{M})$, sulfaphenazole $(0-1 \mu \mathrm{M})$, and ketoconazole $(0-10 \mu \mathrm{M})$ for CYP1A2, CYP2C9, and CYP3A4, respectively. Each value represents the mean \pm S.D. of triplicate determinations.

\begin{tabular}{llll}
\hline & \multicolumn{2}{l}{ Ki value $(\mu \mathrm{M})$} & \\
\cline { 2 - 4 } & CYP1A2 & CYP2C9 & CYP3A4 \\
\hline CG & - & $9.76 \pm 0.47$ & - \\
EGCG & $14.3 \pm 0.09$ & - & $20.1 \pm 0.30$ \\
Selective Inhibitor & $0.65 \pm 0.16$ & $0.67 \pm 0.01$ & $0.05 \pm 0.01$ \\
\hline
\end{tabular}


In conclusion, the ingestion of beverages containing large amounts of green tea catechins with a drug that is metabolized by CYP1A2, CYP2C9, and CYP3A4 should be avoided.

\section{REFERENCES}

1. Cho HJ, Yoon IS. Pharmacokinetic interactions of herbs with cytochrome P450 and P-glycoprotein. Evid Based Complement Alternat Med, 2015; 736431. doi: 10.1155/2015/736431.

2. Cabinet Office, Government of Japan. Survey regarding use of "health food" in consumers (questionnaire survey). http://www.cao.go.jp/consumer/iinkaikouhyou/2012 /houkoku/201205_report.html, 2012; cited on February, 04, $201 \overline{6}$.

3. Satoh T, Fujita K, Munakata M, Itoh S, Nakamura K, Kamataki T, Itoh S, Yoshizawa I. Studies on the interactions between drugs and estrogen: Analytical method for prediction system of gynecomastia induced by drugs on the inhibitory metabolism of estradiol using Escherichia coli coexpressing human CYP3A4 with human NADPH-cytochrome P450 reductase. Anal Biochem, 2000; 286:179-186.

4. Zanger UM, Schwab M. Cytochrome P450 enzymes in drug metabolism: Regulation of gene expression, enzyme activities, and impact of genetic variation. Pharmacol Ther, 2013; 138:103-141. doi: 10.1016/j.pharmthera.2012.12.007.

5. Nguyen S, Huang H, Foster BC, Tam TW, Xing T, Smith ML, Arnason JT, Akhtar H. Antimicrobial and P450 inhibitory properties of common functional foods. J Pharm Pharm Sci, 2014; 17:254-265. doi: http://dx.doi.org/10.18433/J3P599.

6. Liu R, Tam TW, Mao J, Saleem A, Krantis A, Arnason JT, Foster BC. The effect of natural health products and traditional medicines on the activity of human hepatic microsomal-mediated metabolism of oseltamivir. J Pharm Pharm Sci, 2010; 13:43-55. doi: http://dx.doi.org/10.18433/J3ZP42.

7. Tam TW, Akhtar H, Arnason JT, Cvijovic K, Boon H, Cameron DW, Drouin CE, Jaeger W, Tsuyuki RT, Vohra S, Foster BC. Inhibition of human cytochrome P450 metabolism by blended herbal products and vitamins. J Pharm Pharm Sci, 2011; 14:1-16. doi: http://dx.doi.org/10.18433/J3N30W.

8. Tam TW, Liu R, Saleem A, Arnason JT, Krantis A, Foster BC. Cytochrome P450 3A4 and 2D6mediated metabolism of leisure and medicinal teas. J Pharm Pharm Sci, 2014; 17:294-301. doi: http://dx.doi.org/10.18433/J3902H.

9. de Lima Toccafondo Vieira M, Huang SM. Botanical-drug interactions: a scientific perspective. Planta Med, 2012; 78:1400-1415. doi: 10.1055/s0032-1315145.

10. Hermann R, von Richter O. Clinical evidence of herbal drugs as perpetrators of pharmacokinetic drug interactions. Planta Med, 2012; 78:1458-1477. doi: 10.1055/s-0032-1315117.

11. Ruschitzka F, Meier PJ, Turina M, Lüscher TF, Noll G. Acute heart transplant rejection due to St John's wort. Lancet, 2000; 355:548-549.

12. Mathijssen RH, Verweij J, de Bruijn P, Loos WJ, Sparreboom A. Effects of St. John's wort on irinotecan metabolism. J Natl Cancer Inst, 2002; 94:1247-1249.

13. Tsuchida $\mathrm{Y}$, Itakura $\mathrm{H}$, Nakamura $\mathrm{H}$. Reduction of body fat in human by long-term ingestion of catechins. Prog Med, 2002; 22:2189-2203.

14. Kozuma K, Chikama A, Hoshino E, Kataoka K, Mori K, Hase T, Katsuragi Y, Tokimitsu I, Nakamura N. Effect of intake of a beverage containing $540 \mathrm{mg}$ catechins on the body composition of obese women and men. Prog Med, 2005; 25:1945-1957.

15. Ota N, Soga S, Shimotoyodome A, Haramizu S, Inaba M, Murase T, Tokimitsu I. Effects of combination of regular exercise and tea catechins intake on energy expenditure in humans. J Health Sci, 2005; 51:233-236.

16. Yamada K, Sato-Mito N, Nagata J, Umegaki K. Health claim evidence requirements in Japan. J Nutr, 2008; 138:1192S-1198S.

17. Kokubo Y, Iso H, Saito I, Yamagishi K, Yatsuya H, Ishihara J, Inoue M, Tsugame S. The impact of green tea and coffee consumption on the reduced risk of stroke incidence in Japanese population. The Japan public health center-based study cohort. Stroke, 2013; 44:1369-1374. doi: 10.1161/STROKEAHA.111.677500.

18. Sarma DN, Barrett ML, Chavez ML, Gardiner P, Ko L, Mahady GB, Marles RJ, Pellicore LS, Giancaspro GI, Dog TL. Safety of green tea extracts. A systemic review by the US pharmacopeia. Drug Safety, 2008; 31:469-484.

19. Mazzanti G, Menniti-Ippolito F, Moro PA, Cassetti F, Raschetti R, Santuccio C, Mastrangelo S. Hepatotoxicity from green tea: a review of the literature and two unpublished cases. Eur J Clin Pharmacol, 2009; 65:331-341. doi: 10.1007/s00228008-0610-7.

20. Ikeda I, Kobayashi M, Hamada T, Tsuda K, Goto H, Imaizumi K, Nozawa A, Sugimoto A, Kakuda T. Heat-epimerized tea catechins rich in gallocatechin gallate and gatechin gallate are more effective to inhibit cholesterol absorption than tea catechins rich in epigallocatechin gallate and epicatechin gallate. J Agric Food Chem, 2003; 51: 7303-7307.

21. Seto R, Nakamura H, Nanjo F, Hara Y. Preparation of epimers of tea catechins by heat treatment. Biosci Biotech Biochem, 1997; 61: 1434-1439.

22. Lynch T, Price A. The effect of cytochrome P450 metabolism on drug response, interactions, and adverse effects. Am Fam Physician, 2007; 76:391- 
396.

23. Kozakai K, Yamada Y, Oshikata M, Kawase T, Suzuki E, Haramaki Y, Taniguchi H. Reliable highthroughput method for inhibition assay of 8 cytochrome $\mathrm{P} 450$ isoforms using cocktail of probe substrates and stable isotope-labeled internal standards. Drug Metab Pharmacokinet, 2012; 27:520-529.

24. US FDA. Drug development and drug interactions: table of substrates, inhibitors and inducers. U.S. Food and Drug Administration. http://www.fda.gov/Drugs/DevelopmentApprovalPr ocess/DevelopmentResources/DrugInteractionsLabe ling/ucm093664.htm; cited on May, 12, 2016.

25. Muto S, Fujita K, Yamazaki Y, Kamataki T. Inhibition by green tea catechins of metabolic activation of procarcinogens by human cytochrome P450. Mut Res, 2001; 479:197-206.

26. Misaka S, Kawabe K, Onoue S, Werba LP, Girou M., Tamaki S, Kan T, Kimura J, Watanabe H, Yamada S. Effects of green tea catechins on cytochrome P450 2B6, 2C8, 2C19, 2D6 and 3A4 activities in human liver and intestinal microsomes. Drug Metab Pharmacokinet, 2013; 28:244-249.

27. Babich H, Zuckerbraun HL, Weinerman SM. In vitro cytotoxicity of (-)-catechin gallate, a minor polyphenol in green tea. Toxicol Lett, 2007; 171:171-180.

28. Kürbitz C, Heise D, Redmer T, Goumas F, Arlt A, Lemke J, Rimbach G, Kalthoff H, Trauzold A. Epicatechin gallate and catechin gallate are superior to epigallocatechin gallate in growth suppression and anti-inflammatory activities in pancreatic tumor cells. Cancer Sci, 2011; 102:728-734. doi: 10.1111/j.13497006.2011.01870.x.

29. Srtobel P, Allard C, Perez-Acle T, Calderon R, Aldunate R, Leighton F. Myricetin, quercetin and catechin-gallate inhibit glucose uptake in isolated rat adipocytes. Biochem J, 2005; 386:471-478.
30. Imai K, Suga K, Nakachi K. Cancer-preventive effects of drinking green tea among a Japanese population. Prev Med, 1997; 26:769-775.

31. Nakagawa K, Okuda S, Miyazawa T. Dosedependent incorporation of tea catechins, (-)epigallocatechin-3-gallate and (-)-epigallocatechin, into human plasma. Biosci Biotechnol Biochem, 1997; 61:1981-1985.

32. Chow H-HS, Hakin IA, Vining DR, Crowell JA, Ranger-Moore J, Chew WM, Celaya CA, Rodney SR, Hara Y, Alberts DS. Effects of dosing condition on the oral bioavailability of green tea catechins after single-dose administration of polyphenon $\mathrm{E}$ in healthy individuals. Clin Cancer Res, 2005; 11:46274633.

33. Chow H-HS, Cai Y, Alberts DS, Hakin I, Dorr R, Shahi F, Crowell JA, Yang CS, Hara Y. Phase I pharmacokinetic study of tea polyphenols following single-dose administration of epigallocatechin gallate and polyphenon E. Cancer Epidemiol Biomarkers Prev, 2001; 10:53-58.

34. Lee M-J, Maliakal P, Chen L, Meng X, Bondoc FY, Prabhu S, Lambert G, Mohr S, Yang CS. Pharmacokinetics of tea catechins after ingestion of green tea and (-)-epigallocatechin-3-gallate by humans: formation of different metabolites and individual variability. Cancer Epidemiol Biomarkers Prev, 2002; 11:1025-1032.

35. Chow H-HS, Hakin IA, Vining DR, Crowell JA, Cordova CA, Chew WM, Xu MJ, Hus CH, RangerMoore J, Alberts DS. Effects of repeated green tea catechin administration on human cytochrome P450 activity. Cancer Epidemiol Biomarkers Prev, 2006; 15:2473-2476. 